\title{
A propósito del artículo «Prevalencia de enfermedades de transmisión sexual en pacientes con VIH/SIDA»
}

\section{Regarding the article "Prevalence of sexually transmitted diseases in HIVIAIDS patients"}

\author{
Alexandra H. Benavente*, Geylli M. Moreno y Luis A. Llanco \\ Escuela Profesional de Medicina Humana, Universidad Privada San Juan Bautista, Chincha, Ica, Perú
}

Luego de leer el artículo de Santamaría Burgos et al. ${ }^{1}$ titulado «Prevalencia de enfermedades de transmisión sexual en pacientes con VIH/SIDA» consideramos que algunos aspectos no fueron debidamente analizados: el título es muy general, se resalta a enfermedades de trasmisión sexual (ETS) poco frecuentes y el manejo de forma inadecuada de los criterios de inclusión.

Primero, el título no es claro, ya que en las conclusiones solo mencionan la sífilis como ETS más prevalente en los homosexuales, sin presentar ni discutir los resultados del grupo de mujeres.

El papel atribuido a la sífilis en este estudio discrepa de otros, ya que en pacientes infectados por el virus de la inmunodeficiencia humana (VIH) la ETS más prevalente en todo el mundo es el virus del papiloma humano, y los condilomas son las lesiones benignas más frecuentes en la región anogenital. Aunque esta infección afecta a ambos sexos, se han documentado más casos en homosexuales que practican relación anal $\sin$ preservativo ${ }^{2}$, mientras que en las mujeres el riesgo de infección es menor, pero estas pueden desarrollar lesiones neoplásicas del cuello uterino ${ }^{3}$. Así mismo, otro estudio refiere que pacientes infectados por el VIH tienen una alta prevalencia de infección por el virus de la hepatitis $C$, debido a que este comparte similares vías de transmisión ${ }^{4}$.
Por último, considerar como criterio de inclusión ser positivo para sífilis afectó los resultados (ETS más frecuente) y conlleva sesgos, ya que deja de lado otras ETS con mayor prevalencia.

En resumen, el estudio debió considerar otras ETS más prevalentes en pacientes con $\mathrm{VIH}$, tal como se manifiesta en el título, para evitar confusión en los resultados y la conclusiones.

\section{Financiamiento}

Los autores no recibieron patrocinio para llevar a cabo este artículo.

\section{Conflictos de intereses}

Los autores declaran no tener ningún conflicto de intereses.

\section{Responsabilidades éticas}

Protección de personas y animales. Los autores declaran que para esta investigación no se han realizado experimentos en seres humanos ni en animales.

Confidencialidad de los datos. Los autores declaran que han seguido los protocolos de su centro de trabajo sobre la publicación de datos de pacientes.
Correspondencia:

*Alexandra H. Benavente

E-mail: alexandra.benavente@upsjb.edu.pe 0210-5187/@ 2021 Colegio Ibero Latinoamericano de Dermatología A.C. (CILAD). Publicado por Permanyer. Este es un artículo open access bajo la licencia CC BY-NC-ND (http://creativecommons.org/licenses/by-nc-nd/4.0/)

Disponible en internet: 28-01-2022 Med Cutan Iber Lat Am. 2022;50(1):54-55 www.MedicinaCutanealLA.com
un artículo open access bajo la 
Derecho a la privacidad y consentimiento informado. Los autores declaran que en este artículo no aparecen datos de pacientes.

\section{Bibliografía}

1. Santamaría Burgos CG, Oliva Torres CE, Molina Valencia CR, Molina Quimbita JX, Noriega Moreno MM. Prevalencia de enfermedades de transmisión sexual en pacientes con VIH/SIDA. Rev Med Cutanea lbero-Latino-Americana. 2021:48:138-45
2. Sánchez Cárdenas CD, López Salinas G, Ramírez Dóvala S, Juárez Durán ER, Salceda Muñoz PA, Mosqueda Gómez JL, et al. Prevalencia de condilomas ano-genitales en pacientes con infección por VIH en un centro para infecciones de transmisión sexual en León, Guanajuato, México. Rev Chil Infectol. 2021;38:27-30.

3. Jordá GB, Ramos JM, Mosmann J, López ML, Wegert A, Cuffini C. Prevalencia del virus papiloma humano y factores de riesgo asociados en mujeres afiliadas al seguro de salud estatal en Posadas, Misiones (Argentina). Rev Chil Infectol. 2020;37:111-6.

4. Ramírez González LE, Piñeirua Menéndez A, Badial Hernández F, Sánchez Ávila JF, Pérez Carrizosa A, Camiro Zúñiga A, et al. Características demográficas y clínicas de pacientes coinfectados por VIH y virus de hepatitis C en México. Rev Med MD. 2018:9:294-8. 